\title{
Patients with Early-Stage and Estrogen Receptor-Negative Breast Cancers: Young Age Does Link to Poor Outcomes
}

\author{
Yanyan Xie1, Lv Qing1,2, Yao Wang1, Yuting Zhou1, Juanjuan Qiu1, Qianru Yang1, Zhenggui Du1,2* \\ ${ }^{1}$ Department of Breast Surgery, Sichuan University, West China Hospital, Chengdu, China \\ ${ }^{2}$ Laboratory of Breast Disease, Sichuan University, West China Hospital, Chengdu, China \\ Email: ^dulaoshi.jj@163.com
}

How to cite this paper: Xie, Y.Y., Qing, L., Wang, Y., Zhou, Y.T., Qiu, J.J., Yang, Q.R. and Du, Z.G. (2019) Patients with Early-Stage and Estrogen Receptor-Negative Breast Cancers: Young Age Does Link to Poor Outcomes. International Journal of Clinical Medicine, 10, 662-678.

https://doi.org/10.4236/ijcm.2019.1012055

Received: October 21, 2019

Accepted: December 24, 2019

Published: December 27, 2019

Copyright $\odot 2019$ by author(s) and Scientific Research Publishing Inc. This work is licensed under the Creative Commons Attribution International License (CC BY 4.0).

http://creativecommons.org/licenses/by/4.0/

\section{(c) (i) Open Access}

\begin{abstract}
Purpose: This study aimed to evaluate whether young adult breast cancer patients have poor outcomes independent of established prognostic factors and analyze differences in prognosis between younger and older patients stratified by tumor subtype. Methods: Of 10,950 breast cancer patients treated at West China Hospital between 1998 and 2017, 741 younger patients ( $<35$ years) and 3705 older patients ( $\geq 35$ years) were enrolled in this study after applying exclusion criteria and matching adjusted for the diagnosis year. Breast cancer-specific survival (BCSS) and disease-free survival (DFS) were analyzed between the two groups before and after propensity score matching (PSM) as well as in different subgroups. Results: We identified 11 parameters (all $P<$ $0.05)$ that differed between the two groups. Cox regression analysis hazard ratios (HR) for BCSS and DFS in younger patients were 1.604 (95\% CI, 1.327 1.938; $P<0.001)$ and 1.425 (95\% CI, $1.234-1.645 ; P<0.001)$ with reference to the older group. After balancing the differences in baseline characteristics between the two groups by PSM, the HRs for BCSS and DFS of younger patients decreased; however, the differences remained significant (HR for BCSS = 1.328 [95\% CI, $1.038-1.698 ; P=0.024]$ and $\mathrm{HR}$ for $\mathrm{DFS}=1.301$ [95\% CI, 1.077 - 1.572; $P=0.006])$. When stratified by tumor subtype, younger patients with T1, N0, tumor stage I, G3, estrogen receptor (ER)-negative, progesterone receptor (PR)-negative, and Ki67 $\geq 14 \%$ had a poor BCSS; in addition, patients with T1, N1, tumor stages I and II, G3, ER-negative, PR-negative, and triple-negative had a poorer DFS than older patients. Conclusion: Young age was an independent prognostic factor for BCSS and DFS in breast cancer patients. The increased risk of relapse was most pronounced in early-stage breast cancer, especially in patients with ER-negative disease.
\end{abstract}




\section{Keywords}

Breast Cancer, Young Age, Intrinsic Subtype, Propensity Score Matching, Prognosis

\section{Introduction}

Breast cancer is the most common cancer in women worldwide [1] [2]. In European and American countries, the majority of breast cancer patients are postmenopausal women [3]. Breast cancers are relatively rare in young adults, representing a small fraction of cases. Annually, about $6 \%-7 \%$ of all breast cancers are diagnosed in patients under 40 years of age and less than $4 \%$ of patients are younger than 35 years [4] [5]. However, in Asian countries, a higher proportion of breast cancer is diagnosed at a young age, with a mean age at diagnosis about 10 years younger than that in western countries [4] [6]. Therefore, patients, doctors, and health departments should attach due attention to the young age at onset of breast cancers.

Young adults with breast cancer represent a group of patients with special management requirements [7] [8]. In a recent study, the risk of death increased by $5 \%$ for every one-year reduction in age among patients aged $<35$ years, whereas there was no significant correlation between the risk of death and age for patients aged 35 - 50 years [9]. However, in terms of prognosis, the majority of investigators reported that poor survival was not attributed to young age but rather that young adult breast cancer patients usually exhibit higher incidences of advanced stages at diagnosis, human epidermal growth factor receptor 2 (HER2)-positive status, ER or PR-negative status, and a higher histological classification grade than those of older patients [10] [11] [12]. Based on these reports, in recent years, nearly all guidelines no longer regard young age at breast cancer onset to be an independent poor prognostic factor [13]. However, other studies reported that younger age may also be associated with other situations, such as gene mutations or gene methylation, which may independently result in poor outcomes [14] [15]. Thus, whether young age remains an independent predictive prognostic factor, after adjusting for breast cancer subtype (ER, PR, and HER2 status) and other known prognostic factors (tumor stage, adjuvant systemic therapy, etc.), has to be determined.

Therefore, our comprehensive evaluation of breast cancer in young women first applied propensity score matching (PSM) to balance the baseline characteristics between younger and older groups to confirm whether young age $(<35$ years) is an independent risk factor for breast cancer-specific survival (BCSS) and disease-free survival (DFS). We also identified the characteristics of subgroups whose prognosis was most negatively influenced by the early-age onset of breast cancer in order to identify targeted populations of young adult breast cancer patients to receive more effective therapeutic regimens. 


\section{Methods}

\subsection{Patients}

This retrospective analysis included 10,950 breast cancer patients who underwent surgery between 1998 and 2017 at the Department of Breast Surgery at West China Hospital of Sichuan University. The exclusion criteria included metastatic breast cancer, ductal carcinoma in situ, or bilateral breast cancer. We excluded 780 cases, including 375 cases of metastatic breast cancer, 338 cases of ductal carcinoma in situ and 67 cases of bilateral breast cancer. After exclusion, 10,170 patients, including 741 younger patients ( $<35$ years) and 9429 older patients ( $\geq 35$ years), were enrolled in the study. Because there was a stable increase in the proportion of young adult breast cancer patients (from $5.1 \%$ in 1998 to $8.2 \%$ in 2017), we created a matched cohort after adjusting for diagnosis year (1:5) to decrease the differences in survival due to the development of new therapies over time as well as to the difference in sample size between the two groups. Therefore, patients aged $<35$ years at the time of surgery were allocated to the younger group $(N=741)$, while those aged $\geq 35$ years were allocated to the older group $(N=3705)$ (Figure 1$)$.

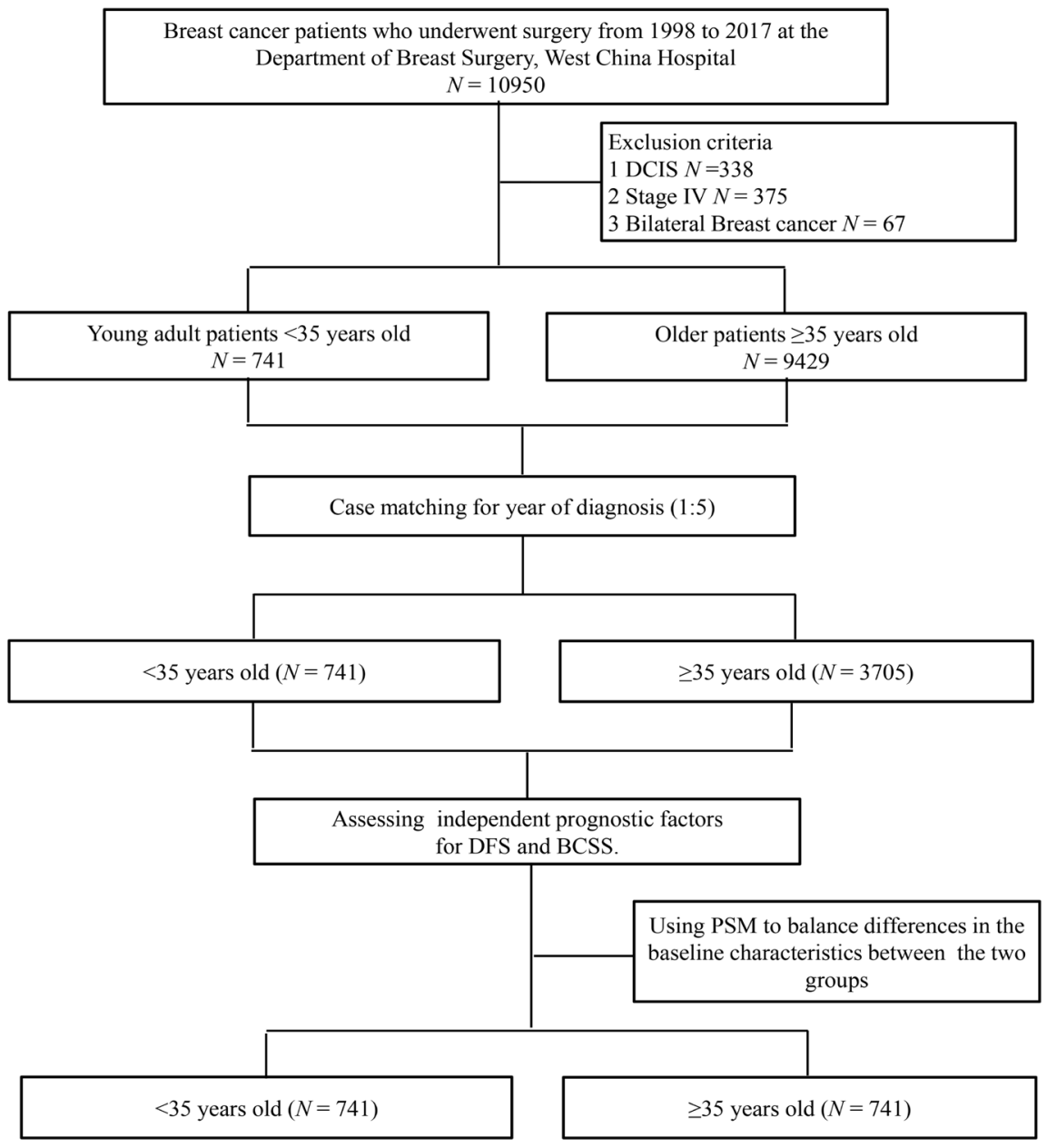

Figure 1. Overview of the study population. 


\subsection{Tumor Stage, Grade, and Subtypes}

Tumor stage was reevaluated using the 8th American Joint Committee on Cancer (AJCC) system [16]. Histologic grade was classified into four groups: well differentiated (G1), moderately differentiated (G2), poorly differentiated and undifferentiated (G3), and unknown. Hormone receptor (HR) status was defined as positive when immunohistochemistry test results for either the ER or PR were positive and as negative when both tests results were negative. HER2 expression was defined as negative when the immunohistochemistry results were negative or $1+$ and as positive when the results were $3+$. When the results were $2+$, we defined the HER2 positivity according to the results of the fluorescent in situ hybridization. According to the St. Gallen classification [17], the breast cancers were categorized into four subtypes: luminal A (HR-positive, HER2-negative, Ki-67 < 14\%); luminal B (HR-positive, HER2-positiveor Ki-67 $\geq 14 \%$ ); HER2 (HR-negative and HER2-positive); and triple negative (TN; HR-negative and HER2-negative).

\subsection{Endpoint Definitions}

The primary endpoints were the incidence of BCSS and DFS. BCSS was defined as the time from the start of treatment to death from breast cancer. Patients who died from causes other than breast cancer are not counted in this measurement. DFS was defined as the length of time from the date of surgery to the appearance of local recurrence, regional metastasis, second primary cancer, distant metastasis, or death.

\subsection{Statistical Analysis}

The descriptive statistics included means, ranges, standard deviations, and proportions. Categorical data are presented as percentages and differences between proportions were compared using chi-square or Fisher's exact tests. BCSS and DFS in two groups were computed using the Kaplan-Meier method and compared using log-rank tests. Univariate and multivariate analyses using Cox regression models with adjusted hazard ratios (HRs) along with 95\% confidence intervals (CIs) were performed to assess the independent prognostic characteristics on DFS or BCSS. PSM was used to balance differences in the baseline characteristics between the younger and older patient groups. The propensity score was calculated using logistic regression including the covariates of $\mathrm{T}$ stage, lymph node metastasis, tumor subtype, histologic grade, and ER status. The adjusted cohort was used to validate the effect of age on outcome. Furthermore, we stratified the cases according to tumor characteristics and analyzed the probabilities of BCSS and DFS according to age. The result was presented as a forest plot. All statistical evaluations were performed using IBM SPSS Statistics for Windows, version 25.0 (IBM Corp., Armonk, NY). Results with $P$ values $<0.05$ were considered statistically significant. This study was reviewed and approved by the Institutional Ethics Committee, West China Hospital of Sichuan University. 


\section{Results}

\subsection{Patient Characteristics and the Association with Age at Diagnosis}

The cohort of patients adjusted for diagnosis year was classified into younger ( $<35$ years, $N=741)$ and older ( $\geq 35$ years, $N=3705)$ age groups. The detailed features of the two groups are presented in Table 1 . Eleven factors, including $\mathrm{T}$ stage, lymph node status, tumor stage, histologic grade, ER status, PR status, HER2 status, Ki-67, tumor subtype, and endocrinotherapy, differed significantly between the two groups. The results of the univariate analysis indicated that tumors in young breast cancer patients were more aggressive than those in older patients.

\subsection{Survival Analysis}

The median follow-up duration was 83 months (range, 3 - 180 months). In total, $603(13.6 \%)$ patients died of breast cancer and 1126 (25.3\%) patients experienced breast cancer recurrence or death. The 15-year BCSS and DFS rates for the younger and older groups were $81.1 \%$ and $87.5 \%$, respectively $(P<0.001$, Figure $2(\mathrm{a}))$ and $68.2 \%$ and $76.0 \%$, respectively $(P<0.001$, Figure $2(\mathrm{~b}))$.Cox regression analysis showed that the HRs for BCSS and DFS in the younger patients were 1.604 (95\% CI, 1.327 - 1.938; $P<0.001$ ) and 1.425 (95\% CI, $1.234-1.645 ; P<$ $0.001)$, respectively, with reference to the older group. Thus, the prognosis of younger breast cancer patients was worse than that of older breast cancer patients. However, we cannot conclude that young age is an independent risk factor of BCSS and DFS because the poor outcomes may be due to more aggressive tumors in the younger patients than those in the older patients. In order to discover whether the poor prognosis among young adults with breast cancer was due to age itself, we set the BCSS and DFS as the research endpoints for Cox regression analysis in Table 2. Univariate analysis showed that all factors except for histologic grade, Ki-67, and radiotherapy could predict the BCSS and all factors except for Ki-67, radiotherapy, and chemotherapy could predict the DFS. Furthermore, the multivariate analysis performed using the factors associated with survival outcomes in univariate analysis revealed that age remained an independent factor associated with BCSS $(P<0.001)$ and DFS $(P<0.001)$.

\subsection{Survival Analysis According to PSM in the Corrected Cohort}

To validate the effect of age on BCSS and DFS, PSM was used to balance the differences in baseline characteristics and generate a corrected cohort. The propensity score was calculated using a logistic regression that included the covariates of all independent risk factors for BCSS and DFS; namely T stage, lymph node status, histologic grade, ER status, and tumor subtype. All covariates were well-balanced between the younger and older groups in the corrected cohort (all $P$ values $>0.260$, Table 3 ). The 15-year BCSS and DFS rates for the younger and older groups were $81.1 \%$ and $84.3 \%(P=0.023$, Figure $3(\mathrm{a}))$ and $68.2 \%$ and 
Table 1. Clinicopathological characteristics and treatment regiments in younger and older breast cancer patients.

\begin{tabular}{|c|c|c|c|c|}
\hline & $\begin{array}{c}<35 \text { years } \\
N=741, \text { No. }(\%)\end{array}$ & $\begin{aligned} & \geq 35 \text { years } \\
N= & 3705, \text { No. }(\%)\end{aligned}$ & $x^{2}$ & $P$-value \\
\hline T stage & & & 11.532 & 0.021 \\
\hline $\mathrm{T} 1$ & $243(32.8)$ & $1279(34.5)$ & & \\
\hline $\mathrm{T} 2$ & $339(45.7)$ & $1795(48.4)$ & & \\
\hline T3 & $91(12.3)$ & $399(10.8)$ & & \\
\hline $\mathrm{T} 4$ & $55(7.4)$ & $198(5.3)$ & & \\
\hline Unknown & $13(1.8)$ & $34(0.9)$ & & \\
\hline Lymph node status & & & 30.096 & $<0.001$ \\
\hline N0 & $294(39.7)$ & $1691(45.6)$ & & \\
\hline $\mathrm{N} 1$ & $210(28.3)$ & $1137(30.7)$ & & \\
\hline N2 & $124(16.7)$ & $535(14.4)$ & & \\
\hline N3 & $113(15.2)$ & $342(9.2)$ & & \\
\hline Tumor stage & & & 26.383 & $<0.001$ \\
\hline 1 & $160(21.6)$ & $904(24.4)$ & & \\
\hline 2 & $314(42.4)$ & $1,808(48.8)$ & & \\
\hline 3 & $260(35.1)$ & $973(26.3)$ & & \\
\hline Unknown & $7(0.9)$ & $20(0.5)$ & & \\
\hline Histologic grade & & & 42.810 & $<0.001$ \\
\hline G1 & $68(9.2)$ & $535(14.4)$ & & \\
\hline G2 & $256(34.5)$ & $1553(41.9)$ & & \\
\hline G3 & $383(51.7)$ & $1470(39.7)$ & & \\
\hline Unknown & $34(4.6)$ & $147(4.0)$ & & \\
\hline ER status & & & 10.130 & 0.001 \\
\hline Negative & $221(22.8)$ & $899(24.3)$ & & \\
\hline Positive & $520(70.2)$ & $2806(75.7)$ & & \\
\hline PR status & & & 4.995 & 0.025 \\
\hline Negative & $225(30.4)$ & $977(26.4)$ & & \\
\hline Positive & $516(69.6)$ & $2728(73.6)$ & & \\
\hline HER2 status & & & 8.097 & 0.017 \\
\hline Negative & $361(48.7)$ & $2016(54.4)$ & & \\
\hline Positive & $180(24.3)$ & $790(21.3)$ & & \\
\hline Unknown & $200(27)$ & $899(24.3)$ & & \\
\hline Ki-67 (\%) & & & 8.710 & 0.013 \\
\hline$<14 \%$ & 277 (37.4) & $1503(40.6)$ & & \\
\hline$\geq 14 \%$ & $438(59.1)$ & $2130(57.5)$ & & \\
\hline Unknown & $26(3.5)$ & $72(1.9)$ & & \\
\hline Tumor subtype & & & 22.173 & $<0.001$ \\
\hline Luminal A & $89(12.0)$ & $604(16.3)$ & & \\
\hline Luminal B & $369(49.8)$ & 1923 (51.9) & & \\
\hline
\end{tabular}




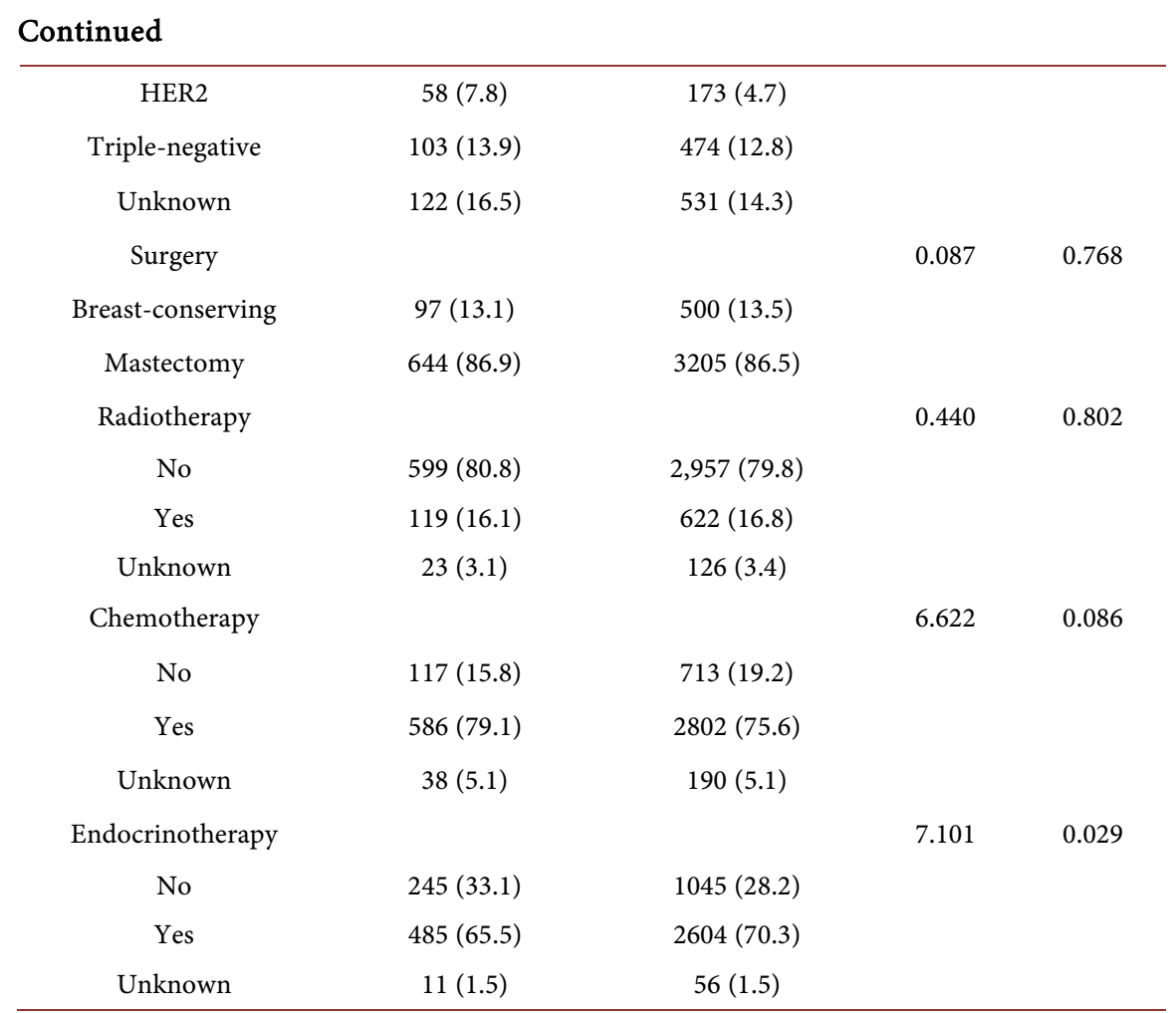

$73.3 \%$, respectively $(P=0.006$, Figure $3(\mathrm{~b}))$. Cox regression analysis showed that the HRs for BCSS and DFS of the younger patients decreased when compared to those in the unmatched cohort; however, the difference remained statistically significant (HR for BCSS $=1.328[95 \% \mathrm{CI}, 1.038-1.698 ; P=0.024]$ and HR for DFS $=1.301[95 \% \mathrm{CI}, 1.077-1.572 ; P=0.006])$.

\subsection{Subgroup Analysis in the Corrected Cohort}

In order to identify the poor outcomes of what kinds of patients were most correlated with young age in this study, subgroup analyses were performed based on all clinicopathological characteristics in the corrected data. The results of BCSS and DFS rates are summarized in Figure 4. Patients in the younger group with T1, N0, tumor stage I, G3, ER-negative, PR-negative, and Ki67 $\geq 14 \%$ had a poorer BCSS compared with that in patients in the older group. Similarly, patients in the younger group with T1, N1, tumor stages I and II, G3, ER-negative, PR-negative, and triple-negative tumors had a poorer DFS compared to that in patients in the older group. In general, younger patients with early-stage tumors and ER-negative had a significantly increased incidence of poor outcomes compared to those of older patients.

\section{Discussion}

Whether young age is an independent risk factor for breast cancer survival is controversial [14] [18] [19] [20]. In this population-based cohort study, we found that young age was highly correlated with progressive tumor characters. 
Table 2. Univariate and multivariate Cox regression analysis of all clinical and pathological parameters.

\begin{tabular}{|c|c|c|c|c|c|c|c|c|}
\hline & \multicolumn{4}{|c|}{ BCSS } & \multicolumn{4}{|c|}{ DFSS } \\
\hline & \multicolumn{2}{|c|}{ Univariate Analysis } & \multicolumn{2}{|c|}{ Multivariate Analysis } & \multicolumn{2}{|c|}{ Univariate Analysis } & \multicolumn{2}{|c|}{ Multivariate Analysis } \\
\hline & OR (95\% CI) & $P$-value & OR $(95 \% \mathrm{CI})$ & $\mathrm{P}$-value & OR (95\% CI) & $P$-value & OR (95\% CI) & $P$-value \\
\hline Age (years) & & $<0.001$ & & $<0.001$ & & $<0.001$ & & $<0.001$ \\
\hline$<35$ & $1.604(1.327-1.938)$ & & $1.529(1.264-1.850)$ & & $1.425(1.234-1.645)$ & & $1.376(1.191-1.589)$ & \\
\hline$\geq 35$ & 1 (ref) & & 1 (ref) & & 1 (ref) & & 1 (ref) & \\
\hline $\mathrm{T}$ stage & & $<0.001$ & & $<0.001$ & & $<0.001$ & & $<0.001$ \\
\hline $\mathrm{T} 1$ & 1 (ref) & & 1 (ref) & & 1 (ref) & & 1 (ref) & \\
\hline $\mathrm{T} 2$ & $2.657(2.106-3.352)$ & & $2.372(1.859-3.026)$ & & $1.574(1.367-1.813)$ & & $1.576(1.368-1.816)$ & \\
\hline $\mathrm{T} 3$ & $4.922(3.772-6.424)$ & & $3.909(2.858-5.348)$ & & $2.139(1.77-2.584)$ & & $2.121(1.755-2.562)$ & \\
\hline $\mathrm{T} 4$ & $3.134(2.174-4.519)$ & & $2.483(1.647-3.744)$ & & $1.420(1.076-1.872)$ & & $1.396(1.059-1.842)$ & \\
\hline Unknown & $4.129(2.149-7.934)$ & & $3.386(1.744-6.576)$ & & $1.800(1.052-3.078)$ & & $1.770(1.034-3.029)$ & \\
\hline Lymph node status & & $<0.001$ & & 0.001 & & 0.003 & & \\
\hline No & 1 (ref) & & & & 1 (ref) & & & \\
\hline N1 & $1.833(1.493-2.251)$ & & $1.451(1.174-1.792)$ & & $1.102(0.958-1.268)$ & & & \\
\hline $\mathrm{N} 2$ & $2.514(2.002-3.156)$ & & $1.600(1.238-2.068)$ & & $1.241(1.045-1.473)$ & & & \\
\hline N3 & $2.664(2.08-3.411)$ & & $1.485(1.11-1.986)$ & & $1.383(1.146-1.669)$ & & & \\
\hline Tumor stage & & $<0.001$ & & 0.503 & & $<0.001$ & & \\
\hline 1 & 1 (ref) & & & & 1 (ref) & & & \\
\hline 2 & $2.773(2.067-3.72)$ & & & & $1.543(1.31-1.816)$ & & & \\
\hline 3 & $4.576(3.407-6.144)$ & & & & $1.748(1.469-2.081)$ & & & \\
\hline Unknown & $3.476(1.258-9.605)$ & & & & $1.149(0.473-2.791)$ & & & \\
\hline Histologic grade & & 0.177 & & - & & 0.001 & & 0.002 \\
\hline G1 & 1 (ref) & & & & 1 (ref) & & 1 (ref) & \\
\hline G2 & $0.997(0.766-1.299)$ & & & & $1.040(0.855-1.264)$ & & $1.019(0.838-1.239)$ & \\
\hline G3 & $1.192(0.921-1.542)$ & & & & $1.269(1.049-1.535)$ & & $1.232(1.018-1.491)$ & \\
\hline Unknown & $1.230(0.795-1.901)$ & & & & $1.491(1.095-2.029)$ & & $1.497(1.099-2.039)$ & \\
\hline ER & & $<0.001$ & & 0.827 & & 0.010 & & 0.029 \\
\hline Positive & 1 (ref) & & & & 1 (ref) & & 1 (ref) & \\
\hline Negative & $0.701(0.591-0.831)$ & & & & $0.843(0.74-0.959)$ & & $0.865(0.759-0.985)$ & \\
\hline PR & & $<0.001$ & & 0.782 & & 0.048 & & \\
\hline Positive & 1 (ref) & & & & 1 (ref) & & & \\
\hline Negative & $0.726(0.614-0.860)$ & & & & $0.879(0.773-0.999)$ & & & \\
\hline HER2 & & $<0.001$ & & 0.845 & & 0.011 & & \\
\hline Positive & 1 (ref) & & & & 1 (ref) & & & \\
\hline Negative & $1.393(1.144-1.695)$ & & & & $1.237(1.071-1.429)$ & & & \\
\hline Unknown & $1.366(1.128-1.653)$ & & & & $1.137(0.986-1.31)$ & & & \\
\hline Ki-67(\%) & & 0.258 & & - & & 0.783 & & \\
\hline$<14 \%$ & 1 (ref) & & & & 1 (ref) & & & \\
\hline$\geq 14 \%$ & $1.100(0.933-1.298)$ & & & & $1.009(0.895-1.137)$ & & & \\
\hline
\end{tabular}




\section{Continued}

\begin{tabular}{|c|c|c|c|c|c|c|}
\hline Unknown & $0.725(0.385-1.365)$ & & & & $0.870(0.572-1.323)$ & \\
\hline Tumor subtype & & $<0.001$ & & 0.001 & & 0.001 \\
\hline Luminal A & 1 (ref) & & 1 (ref) & & 1 (ref) & \\
\hline Luminal B & $1.266(0.978-1.639)$ & & $1.009(0.777-1.311)$ & & $1.037(0.873-1.233)$ & \\
\hline HER2 & $2.378(1.683-3.361)$ & & $1.462(1.028-2.079)$ & & $1.634(1.26-2.12)$ & \\
\hline Triple Negative & $1.617(1.185-2.207)$ & & $1.516(1.11-2.071)$ & & $1.038(0.828-1.301)$ & \\
\hline Unknown & $1.490(1.099-2.021)$ & & $0.922(0.674-1.261)$ & & $1.187(0.961-1.465)$ & \\
\hline Surgery & & $<0.001$ & & 0.377 & & $<0.001$ \\
\hline Breast-conserving & 1 (ref) & & & & 1 (ref) & \\
\hline Mastectomy & $2.101(1.541-2.865)$ & & & & $1.419(1.171-1.720)$ & \\
\hline Radiotherapy & & 0.820 & & - & & 0.665 \\
\hline Yes & 1 (ref) & & & & 1 (ref) & \\
\hline No & $1.047(0.798-1.373)$ & & & & $1.047(0.897-1.222)$ & \\
\hline Unknown & $0.89(0.57-1.392)$ & & & & $0.895(0.639-1.255)$ & \\
\hline Chemotherapy & & 0.001 & & 0.421 & & 0.264 \\
\hline Yes & 1 (ref) & & & & 1 (ref) & \\
\hline No & $2.932(1.655-5.194)$ & & & & $1.136(0.974-1.326)$ & \\
\hline Unknown & $2.695(1.38-5.264)$ & & & & $1.080(0.807-1.445)$ & \\
\hline Endocrinotherapy & & $<0.001$ & & 0.478 & & 0.028 \\
\hline No & 1 (ref) & & & & 1 (ref) & \\
\hline Yes & $0.698(0.591-0.824)$ & & & & $0.858(0.756-0.973)$ & \\
\hline Unknown & $0.867(0.445-1.688)$ & & & & $1.185(0.755-1.859)$ & \\
\hline
\end{tabular}

The survival analysis also indicated that young age ( $<35$ years) at diagnosis was associated with unfavorable clinical outcomes in women with breast cancer in both the unadjusted and adjusted cohorts, especially patients in the early-stage and ER-negative subgroups.

A number of studies have focused on the prognosis of young and old age at diagnosis of breast cancer. Some have reported young age to be an independent risk factor for relapse in operable breast cancer patients [21] [22] [23]; however, others reported that age is not significantly related to mortality from breast cancer when accounting for all prognostic variables [10] [12] [19]. The inconsistent results may be due to differences in the definitions of young age in these studies, such as that under the ages of 30, 35, 40, or even 45 years [8] [24]-[29]. In clinical practice, an optimal cutoff value is needed to define young patients with breast cancer. The Suppression of Ovarian Function Trial (SOFT) showed that ovarian function suppression (OFS) did not provide a significant benefit to the overall study population but did improve disease outcomes in younger patients ( $<35$ years) [30]. After consulting experts and the literature, St Gallen adopted acutoff of 35 years to define the risk categories of breast cancer patients [26]. Therefore, our population-based cohort study used 35 years as the cutoff to 
Table 3. Univariate analysis of matched factors between younger and older breast cancer patients in the corrected cohort.

\begin{tabular}{|c|c|c|c|c|}
\hline & $\begin{array}{c}<35 \text { years } \\
N=741, \text { No. }(\%)\end{array}$ & $\begin{array}{c}\geq 35 \text { years } \\
N=741, \text { No. }(\%)\end{array}$ & $x^{2}$ & $P$-value \\
\hline T stage & & & 4.521 & 0.340 \\
\hline $\mathrm{T} 1$ & $243(32.8)$ & $213(28.7)$ & & \\
\hline $\mathrm{T} 2$ & $339(45.7)$ & $358(48.3)$ & & \\
\hline $\mathrm{T} 3$ & $91(12.3)$ & $107(14.4)$ & & \\
\hline $\mathrm{T} 4$ & $55(7.4)$ & $54(7.3)$ & & \\
\hline Unknown & $13(1.8)$ & $9(1.2)$ & & \\
\hline Lymph node status & & & 3.134 & 0.371 \\
\hline No & $294(39.7)$ & $268(36.2)$ & & \\
\hline N1 & $210(28.3)$ & $236(31.8)$ & & \\
\hline $\mathrm{N} 2$ & $124(16.7)$ & $131(17.7)$ & & \\
\hline N3 & $113(15.2)$ & $106(14.3)$ & & \\
\hline Tumor stage & & & 2.555 & 0.465 \\
\hline 1 & $160(21.6)$ & $137(18.5)$ & & \\
\hline 2 & $314(42.4)$ & $335(45.2)$ & & \\
\hline 3 & $260(35.1)$ & $263(35.5)$ & & \\
\hline Unknown & $7(0.9)$ & $6(0.8)$ & & \\
\hline Histologic grade & & & 3.976 & 0.264 \\
\hline G1 & $68(9.2)$ & $70(9.4)$ & & \\
\hline G2 & $256(34.5)$ & $279(37.7)$ & & \\
\hline G3 & $383(51.7)$ & $348(47)$ & & \\
\hline Unknown & $34(4.6)$ & $44(5.9)$ & & \\
\hline ER & & & 0.396 & 0.529 \\
\hline Negative & $221(22.8)$ & $210(28.3)$ & & \\
\hline Positive & $520(70.2)$ & $531(71.7)$ & & \\
\hline Tumor subtype & & & 5.281 & 0.260 \\
\hline Luminal A & $89(12.0)$ & $115(15.5)$ & & \\
\hline Luminal B & $369(49.8)$ & $348(47)$ & & \\
\hline HER2 & $58(7.8)$ & $47(6.3)$ & & \\
\hline Triple-negative & $103(13.9)$ & $102(13.8)$ & & \\
\hline Unknown & $122(16.5)$ & $129(17.4)$ & & \\
\hline
\end{tabular}

define young breast cancer patients.

Using this definition, we observed a continuous increase in the proportion of young breast cancer patients (from $5.1 \%$ in 1998 to $8.2 \%$ in 2017). In the past two decades, the treatment of breast cancer has changed significantly. Thus, relatively more young patients underwent modern therapies and more old patients underwent the old treatments two decades ago. Therefore, we created a matched cohort adjusted for diagnosis year to eliminate the effects of different therapies 


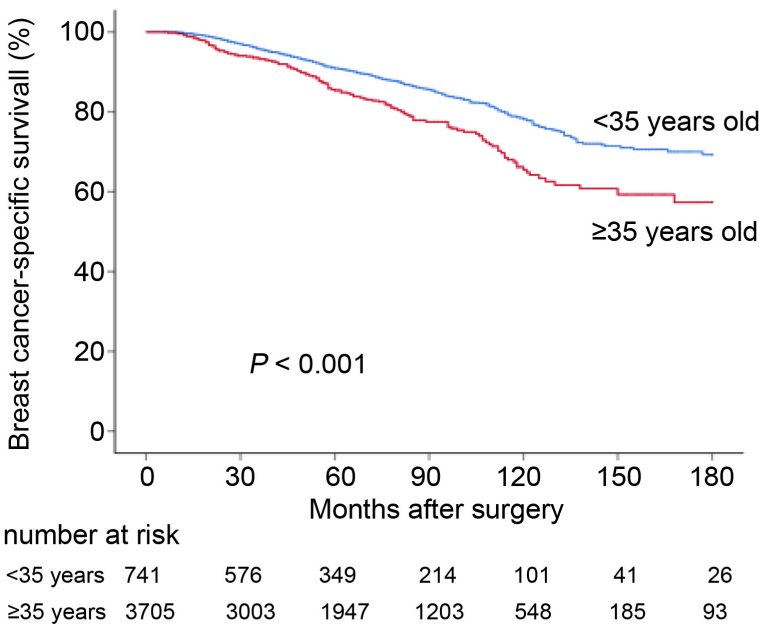

(a)

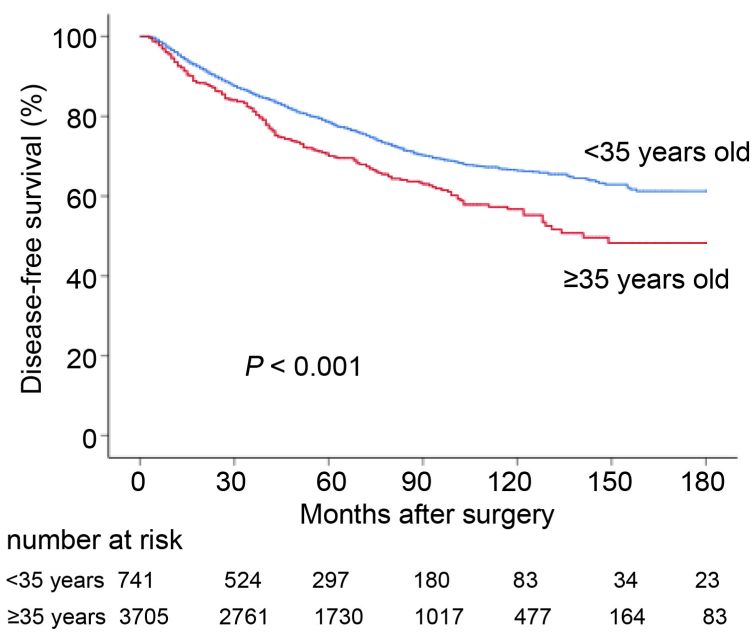

(b)

Figure 2. Kaplan-Meier curves showing breast cancer cancer-specific survival (a) and disease disease-free survival (b) with respect to age at diagnosis.

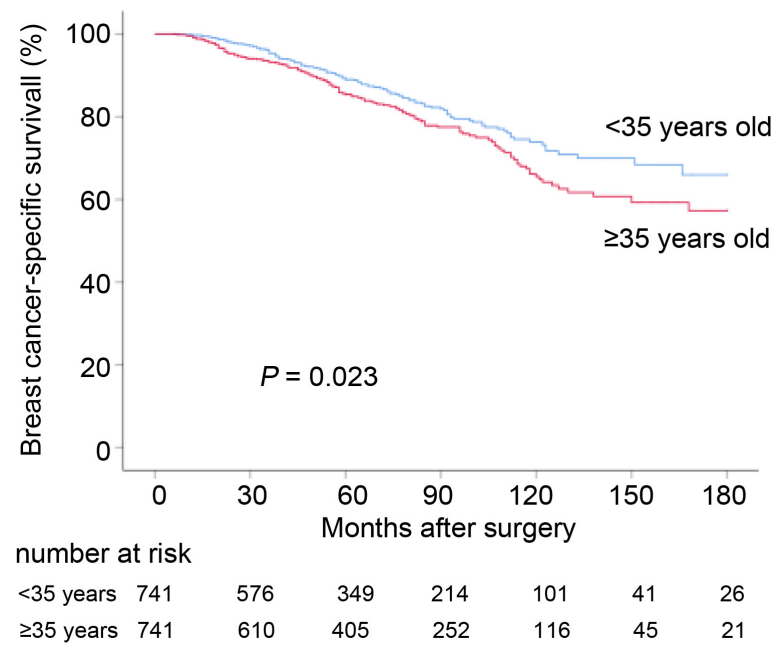

(a)

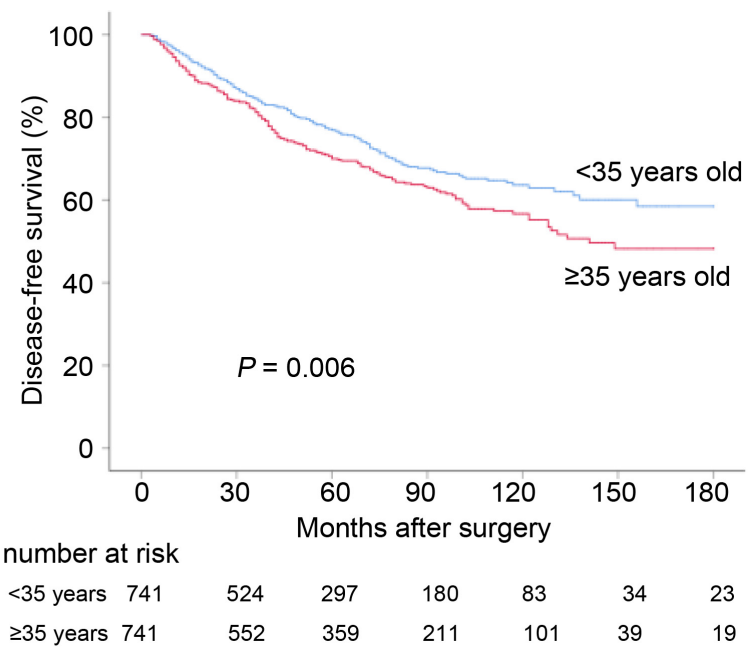

(b)

Figure 3. Kaplan-Meier curves showing breast cancer cancer-specific survival (a) and disease disease-free survival (b) with respect to age at diagnosis in the corrected cohort.

in over time. Many previous studies did not match the age at diagnosis of breast cancer, which may also contribute to the inconsistent results.

In this study, young breast cancer patients were more likely to have a higher $\mathrm{T}$ grade, proportion of histological grade III, ER and PR-negative status, HER-2 overexpression, TNBC subtype, higher stage, and an increased possibility of lymph node invasion, a finding consistent with other literature [10] [12] [31]. Therefore, it is reasonable that young breast cancer patients had a worse prognosis than that of older patients due to the more aggressive nature of the tumors. However, we cannot conclude that young age is an independent prognostic factor. To elucidate the individual role of young age on survival outcomes, we used PSM to balance differences in baseline characteristics correlated with BCSS or 


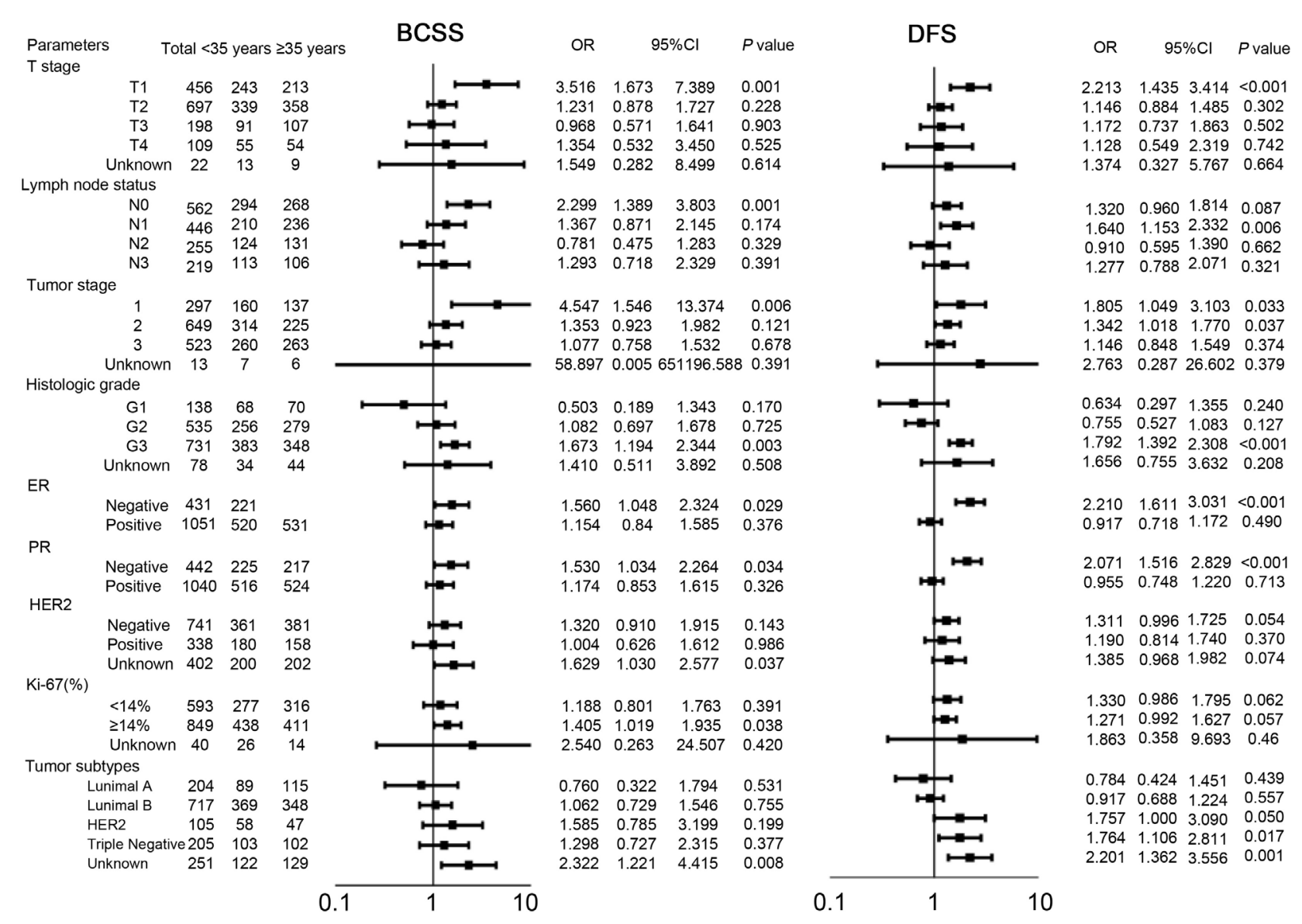

Figure 4. Stratified analysis according to variable and the probability of breast cancer cancer-specific survival analysis and disease disease-free survival according to age.

DFS between the two groups. We found that patients in the younger group had poorer BCSS and DFS compared to those of the patients in the older group. This result showed that, in addition to the aggressive parameters we have already known, other characteristics may also affect the survival of young breast cancer patients. For example, gene expression or molecular biological characteristics in young patients with breast cancer also reportedly contribute to the poor prognosis [32] [33] [34].

As young age at diagnosis of breast cancer appeared to affect patient survival in some way, it remained undetermined if this factor affected all subgroups of breast cancer patients. To answer this question, we performed subgroup analysis and demonstrated that young patients with breast cancer had poorer survival outcomes mainly in the early-stage and ER-negative subgroups. Most of researchers reported that younger patients showed a worse prognosis than that of older patients in ER-positive subgroups [10] [28] [35]. In contrast, just like the other researchers reported [19], our current study showed similar prognosis for younger and older ER-positive patients. The reason for this finding may be due to the fact that up to $73 \%$ of ER-positive patients in the younger group underwent adjuvant chemotherapy and more than one-third chose more aggressive 
endocrinotherapy such as OFS. Younger patients with ER-negative disease had a worse prognosis, especially those with early-stage disease. One the reason for this observation is that the younger patients, especially those with ER-negative tumors, may have a number of micrometastases [36]. Thus, the results of this study, suggest that younger patients with early-stage and ER-negative breast cancer should undergo more aggressive treatment because traditional treatments may be insufficient.

Our study has several potential limitations. Retrospective analyses always carry a risk of various biases. However, with the use of a large-scale sample size, subgroup analysis, and PSM, our study minimized potential biases and had a high degree of power. Moreover, previous literature mainly analyzed young breast cancer with worse prognosis, rarely indicating whether age was an independent risk factor. Our study not only showed that young age was an independent risk factor for breast cancer but subgroup analysis also revealed that age mainly affected the prognosis of early-stage and ER-negative breast cancers. Although no prospective study has demonstrated young age to be an independent prognostic factor, it should be regarded as a risk predictor for survival. Treatment of breast cancer should consider age in association with other pathological and biological factors so that young breast cancer patients can receive more effective therapeutic regimens.

\section{Conclusion}

Young age was an independent prognostic factor of BCSS and DFS for breast cancer patients. The excess risk of relapse was most pronounced in early-stage breast cancer, especially in ER-negative tumors.

\section{Conflicts of Interest}

The authors do not have any disclosures to report.

\section{Ethical Standards}

This study was reviewed and approved by the Institutional Ethics Committee, West China Hospital of Sichuan University.

\section{Financial Support}

This study was supported by a grant from the Natural Science Foundation of China (No. 81400652), the supporting projects of the Science and Technology Department, Sichuan Province (2015SZ0236) and the Key Program of the Science and Technology Bureau of Sichuan (No. 2018SZ0052).

\section{Data Availability}

The datasets generated during and/or analysed during the current study are not publicly available due our data base runs on a local area network but are available from the corresponding author on reasonable request. 


\section{References}

[1] Ginsburg, O., Bray, F., Coleman, M.P., Vanderpuye, V., Eniu, A., Kotha, S.R., Sarker, M., Huong, T.T., Allemani, C., Dvaladze, A., Gralow, J., Yeates, K., Taylor, C., Oomman, N., Krishnan, S., Sullivan, R., Kombe, D., Blas, M.M., Parham, G., Kassami, N. and Conteh, L. (2017) The Global Burden of Women's Cancers: A Grand Challenge in Global Health. The Lancet, 389, 847-860. https://doi.org/10.1016/S0140-6736(16)31392-7

[2] Farouk, O., Ebrahim, M.A., Senbel, A., Emarah, Z., Abozeed, W., Seisa, M.O., Mackisack, S., Jalil, S.A. and Abdelhady, S. (2016) Breast Cancer Characteristics in Very Young Egyptian Women $\leq 35$ Years. Breast Cancer Targets \& Therapy, 8, 53. https://doi.org/10.2147/BCTT.S99350

[3] Baatjes, K.J., Apffelstaedt, J.P., Kotze, M.J. and Conradie, M. (2016) Postmenopausal Breast Cancer, Aromatase Inhibitors, and Bone Health: What the Surgeon Should Know. World Journal of Surgery, 40, 2149-2156. https://doi.org/10.1007/s00268-016-3555-5

[4] Yoon, T.I., Hwang, U.K., Kim, E.T., Lee, S., Sohn, G., Ko, B.S., Lee, J.W., Son, B.H., Kim, S., Ahn, S.H. and Kim, H.J. (2017) Survival Improvement in Hormone-Responsive Young Breast Cancer Patients with Endocrine Therapy. Breast Cancer Research and Treatment, 165, 311-320. https://doi.org/10.1007/s10549-017-4331-4

[5] Chen, H.L., Zhou, M.Q., Tian, W., Meng, K.X. and He, H.F. (2016) Effect of Age on Breast Cancer Patient Prognoses: A Population-Based Study Using the SEER 18 Database. PLoS ONE, 11, e0165409. https://doi.org/10.1371/journal.pone.0165409

[6] Sivasubramaniam, P.G., Zhang, B.L., Zhang, Q., Smith, J.S., Zhang, B., Tang, Z.H., Chen, G.J., Xie, X.M., Xu, X.Z., Yang, H.J., He, J.J., Li, H., Li, J.Y., Fan, J.H. and Qiao, Y.L. (2015) Breast Cancer Disparities: A Multicenter Comparison of Tumor Diagnosis, Characteristics, and Surgical Treatment in China and the U.S. Oncologist, 20, 1044-1050. https://doi.org/10.1634/theoncologist.2014-0290

[7] Zebrack, B. (2008) Information and Service Needs for Young Adult Cancer Patients. Support Care Cancer, 16, 1353-1360. https://doi.org/10.1007/s00520-008-0435-Z

[8] Passhak, M., Shachar, S.S. Bar-Sela, G. and Fried, G. (2018) Breast Cancer in Young Women Aged 35 and Under: Patterns of Care and Outcome. The Breast Journal, 24, 441-443. https://doi.org/10.1111/tbj.12966

[9] Han, W. and Kang, S.Y. (2010) Relationship between Age at Diagnosis and Outcome of Premenopausal Breast Cancer: Age Less than 35 Years Is a Reasonable Cut-Off for Defining Young Age-Onset Breast Cancer. Breast Cancer Research and Treatment, 119, 193-200. https://doi.org/10.1007/s10549-009-0388-Z

[10] Colleoni, M., Rotmensz, N., Peruzzotti, G., Maisonneuve, P., Orlando, L., Ghisini, R., Viale, G., Pruneri, G., Veronesi, P., Luini, A., Intra, M., Cardillo, A., Torrisi, R., Rocca, A. and Goldhirsch, A. (2006) Role of Endocrine Responsiveness and Adjuvant Therapy in Very Young Women (below 35 Years) with Operable Breast Cancer and Node Negative Disease. Annals of Oncology, 17, 1497-1503.

https://doi.org/10.1093/annonc/mdl145

[11] Collins, L.C., Marotti, J.D., Gelber, S., Cole, K., Ruddy, K., Kereakoglow, S., Brachtel, E.F., Schapira, L., Come, S.E., Winer, E.P. and Partridge, A.H. (2012) Pathologic Features and Molecular Phenotype by Patient Age in a Large Cohort of Young Women with Breast Cancer. Breast Cancer Research and Treatment, 131, 1061-1066. https://doi.org/10.1007/s10549-011-1872-9

[12] Partridge, A.H., Hughes, M.E., Warner, E.T., Ottesen, R.A., Wong, Y.N., Edge, S.B., Theriault, R.L., Blayney, D.W., Niland, J.C., Winer, E.P., Weeks, J.C. and Tamimi, 
R.M. (2016) Subtype-Dependent Relationship between Young Age at Diagnosis and Breast Cancer Survival. Journal of Clinical Oncology, 34, 3308-3314. https://doi.org/10.1200/JCO.2015.65.8013

[13] Goldhirsch, A., Ingle, J.N., Gelber, R.D., Coates, A.S., Thurlimann, B. and Senn, H.J. (2009) Thresholds for Therapies: Highlights of the St Gallen International Expert Consensus on the Primary Therapy of Early Breast Cancer 2009. Annals of Oncology, 20, 1319-1329. https://doi.org/10.1093/annonc/mdp322

[14] Anders, C.K., Hsu, D.S., Broadwater, G., Acharya, C.R., Foekens, J.A., Zhang, Y., Wang, Y., Marcom, P.K., Marks, J.R., Febbo, P.G., Nevins, J.R., Potti, A. and Blackwell, K.L. (2008) Young Age at Diagnosis Correlates with Worse Prognosis and Defines a Subset of Breast Cancers with Shared Patterns of Gene Expression. Journal of Clinical Oncology, 26, 3324-3330. https://doi.org/10.1200/JCO.2007.14.2471

[15] Wang, M.X., Ren, J.T., Tang, L.Y. and Ren, Z.F. (2018) Molecular Features in Young vs Elderly Breast Cancer Patients and the Impacts on Survival Disparities by Age at Diagnosis. Cancer Medicine, 7, 3269-3277. https://doi.org/10.1002/cam4.1544

[16] Lee, S.B., Sohn, G., Kim, J., Chung, I.Y., Lee, J.W., Kim, H.J., Ko, B.S., Son, B.H. and Ahn, S.H. (2018) A Retrospective Prognostic Evaluation Analysis Using the 8th Edition of the American Joint Committee on Cancer Staging System for Breast Cancer. Breast Cancer Research and Treatment, 169, 257-266. https://doi.org/10.1007/s10549-018-4682-5

[17] Goldhirsch, A., Winer, E.P., Coates, A.S., Gelber, R.D., Piccart-Gebhart, M., Thurlimann, B. and Senn, H.J. (2013) Personalizing the Treatment of Women with Early Breast Cancer: Highlights of the St Gallen International Expert Consensus on the Primary Therapy of Early Breast Cancer 2013. Annals of Oncology, 24, 2206-2223. https://doi.org/10.1093/annonc/mdt303

[18] Azim, H.A., Michiels, S., Bedard, P.L., Singhal, S.K., Criscitiello, C., Ignatiadis, M., Haibe-Kains, B., Piccart, M.J., Sotiriou, C. and Loi, S. (2012) Elucidating Prognosis and Biology of Breast Cancer Arising in Young Women Using Gene Expression Profiling. Clinical Cancer Research, 18, 1341-1351. https://doi.org/10.1158/1078-0432.CCR-11-2599

[19] Cancello, G., Maisonneuve, P., Rotmensz, N., Viale, G., Mastropasqua, M.G., Pruneri, G., Veronesi, P., Torrisi, R., Montagna, E., Luini, A., Intra, M., Gentilini, O., Ghisini, R., Goldhirsch, A. and Colleoni, M. (2010) Prognosis and Adjuvant Treatment Effects in Selected Breast Cancer Subtypes of Very Young Women $(<35$ Years) with Operable Breast Cancer. Annals of Oncology, 21, 1974-1981. https://doi.org/10.1093/annonc/mdq072

[20] Sheridan, W., Scott, T., Caroline, S., Yvonne, Z., Vanessa, B., David, V., Karen, G. and Stephen, C. (2014) Breast Cancer in Young Women: Have the Prognostic Implications of Breast Cancer Subtypes Changed over Time? Breast Cancer Research and Treatment, 147, 617-629. https://doi.org/10.1007/s10549-014-3125-1

[21] Fredholm, H., Magnusson, K., Lindstrom, L.S., Garmo, H., Falt, S.E., Lindman, H., Bergh, J., Holmberg, L., Ponten, F., Frisell, J. and Fredriksson, I. (2016) Long-Term Outcome in Young Women with Breast Cancer: A Population-Based Study. Breast Cancer Research and Treatment, 160, 131-143. https://doi.org/10.1007/s10549-016-3983-9

[22] Kataoka, A., Iwamoto, T., Tokunaga, E., Tomotaki, A., Kumamaru, H., Miyata, H., Niikura, N., Kawai, M., Anan, K., Hayashi, N., Masuda, S., Tsugawa, K., Aogi, K., Ishida, T., Masuoka, H., Iijima, K., Kinoshita, T., Nakamura, S. and Tokuda, Y. (2016) Young Adult Breast Cancer Patients Have a Poor Prognosis Independent of 
Prognostic Clinicopathological Factors: A Study from the Japanese Breast Cancer Registry. Breast Cancer Research and Treatment, 160, 163-172. https://doi.org/10.1007/s10549-016-3984-8

[23] Arvold, N.D., Taghian, A.G., Niemierko, A., Abi Raad, R.F., Sreedhara, M., Nguyen, P.L., Bellon, J.R., Wong, J.S., Smith, B.L. and Harris, J.R. (2011) Age, Breast Cancer Subtype Approximation, and Local Recurrence after Breast-Conserving Therapy. Journal of Clinical Oncology, 29, 3885-3891. https://doi.org/10.1200/JCO.2011.36.1105

[24] Fu, J., Wu, L., Fu, W., Tan, Y., Xu, T., Hong, Z., Wang, F. and Li, S. (2018) How Young Is Too Young in Breast Cancer? Young Breast Cancer Is Not a Unique Biological Subtype. Clinical Breast Cancer, 18, e25-e39.

https://doi.org/10.1016/j.clbc.2017.05.015

[25] Partridge, A.H., Pagani, O., Abulkhair, O., Aebi, S., Amant, F., Azim, H.A., Costa, A., Delaloge, S., Freilich, G., Gentilini, O.D., Harbeck, N., Kelly, C.M., Loibl, S., Meirow, D., Peccatori, F., Kaufmann, B. and Cardoso, F. (2014) First International Consensus Guidelines for Breast Cancer in Young Women (BCY1). Breast (Edinburgh, Scotland), 23, 209-220. https://doi.org/10.1016/j.breast.2014.03.011

[26] Coates, A.S., Winer, E.P., Goldhirsch, A., Gelber, R.D., Gnant, M., Piccart-Gebhart, M., Thurlimann, B. and Senn, H.J. (2015) Tailoring Therapies-Improving the Management of Early Breast Cancer: St Gallen International Expert Consensus on the Primary Therapy of Early Breast Cancer 2015. Annals of Oncology, 26, 1533-1546. https://doi.org/10.1093/annonc/mdv221

[27] Goldhirsch, A., Wood, W.C., Gelber, R.D., Coates, A.S., Thurlimann, B. and Senn, H.J. (2007) Progress and Promise: Highlights of the International Expert Consensus on the Primary Therapy of Early Breast Cancer 2007. Annals of Oncology, 18, 1133-1144. https://doi.org/10.1093/annonc/mdm271

[28] Ahn, S.H., Son, B.H., Kim, S.W., Kim, S.I., Jeong, J., Ko, S.S. and Han, W. (2007) Poor Outcome of Hormone Receptor-Positive Breast Cancer at Very Young Age Is Due to Tamoxifen Resistance: Nationwide Survival Data in Korea-A Report from the Korean Breast Cancer Society. Journal of Clinical Oncology, 25, 2360-2368. https://doi.org/10.1200/JCO.2006.10.3754

[29] van Laar, C., van der Sangen, M.J., Poortmans, P.M., Nieuwenhuijzen, G.A., Roukema, J.A., Roumen, R.M., Tjan-Heijnen, V.C. and Voogd, A.C. (2013) Local Recurrence Following Breast-Conserving Treatment in Women Aged 40 Years or Younger: Trends in Risk and the Impact on Prognosis in a Population-Based Cohort of 1143 Patients. European Journal of Cancer, 49, 3093-3101. https://doi.org/10.1016/j.ejca.2013.05.030

[30] Saha, P., Regan, M.M., Pagani, O., Francis, P.A., Walley, B.A., Ribi, K., Bernhard, J., Luo, W., Gomez, H.L., Burstein, H.J., Parmar, V., Torres, R., Stewart, J., Bellet, M., Perello, A., Dane, F., Moreira, A., Vorobiof, D., Nottage, M., Price, K.N., Coates, A.S., Goldhirsch, A., Gelber, R.D., Colleoni, M. and Fleming, G.F. (2017) Treatment Efficacy, Adherence, and Quality of Life among Women Younger than 35 Years in the International Breast Cancer Study Group TEXT and SOFT Adjuvant Endocrine Therapy Trials. Journal of Clinical Oncology, 35, 3113-3122.

https://doi.org/10.1200/JCO.2016.72.0946

[31] Kataoka, A., Tokunaga, E., Masuda, N., Shien, T., Kawabata, K. and Miyashita, M. (2014) Clinicopathological Features of Young Patients (<35 Years of Age) with Breast Cancer in a Japanese Breast Cancer Society Supported Study. Breast Cancer, 21, 643-650. https://doi.org/10.1007/s12282-013-0466-2

[32] Honrado, E., Benitez, J. and Palacios, J. (2005) The Molecular Pathology of Heredi- 
tary Breast Cancer: Genetic Testing and Therapeutic Implications. Modern Pathology, 18, 1305-1320. https://doi.org/10.1038/modpathol.3800453

[33] (2012) Comprehensive Molecular Portraits of Human Breast Tumours. Nature, 490, 61-70. https://doi.org/10.1038/nature11412

[34] Azim, H.A. and Partridge, A.H. (2014) Biology of Breast Cancer in Young Women. Breast Cancer Research, 16, 427. https://doi.org/10.1186/s13058-014-0427-5

[35] Kim, E.K., Noh, W.C., Han, W. and Noh, D.Y. (2011) Prognostic Significance of Young Age (< 35 Years) by Subtype Based on ER, PR, and HER2 Status in Breast Cancer: A Nationwide Registry-Based Study. World Journal of Surgery, 35, 1244-1253. https://doi.org/10.1007/s00268-011-1071-1

[36] Mansi, J., Morden, J., Bliss, J.M., Neville, M. and Coombes, R.C. (2016) Bone Marrow Micrometastases in Early Breast Cancer-30-Year Outcome. British Journal of Cancer, 114, 243-247. https://doi.org/10.1038/bjc.2015.447

\section{Abbreviations}

BCSS, Breast cancer-specific survival; DFS, Disease-free survival; PSM, Propensity score matching; HR, Hazard ratios; ER, Estrogen receptor; PR, Progesterone receptor. 